\title{
A Spherical Video-Based Immersive Virtual Reality Learning System to Support Landscape Architecture Students' Learning Performance during the COVID-19 Era
}

\author{
Wei-Long $\mathrm{Wu}^{1}{ }^{1}$, , Yen Hsu ${ }^{1, *(\mathbb{D}}$, Qi-Fan Yang ${ }^{2}\left(\mathbb{D}\right.$ and Jiang-Jie Chen ${ }^{1}(\mathbb{D}$ \\ 1 The Graduate Institute of Design Science, Tatung University, Tapei 104, Taiwan; \\ d10817013@ms.ttu.edu.tw (W.-L.W.); d10717016@ms.ttu.edu.tw (J.-J.C.) \\ 2 College of Education, Fujian Normal University, Fuzhou 350117, China; yangqifan@fjnu.edu.cn \\ * Correspondence: yhsu@gm.ttu.edu.tw; Tel.: +886-221822928 (ext. 6731)
}

\section{check for} updates

Citation: Wu, W.-L.; Hsu, Y.; Yang, Q.-F.; Chen, J.-J. A Spherical Video-Based Immersive Virtual Reality Learning System to Support Landscape Architecture Students' Learning Performance during the COVID-19 Era. Land 2021, 10, 561. https://doi.org/10.3390/

land10060561

Academic Editor: Carlos

Carbonell Carrera

Received: 20 April 2021

Accepted: 24 May 2021

Published: 27 May 2021

Publisher's Note: MDPI stays neutral with regard to jurisdictional claims in published maps and institutional affiliations.

Copyright: (c) 2021 by the authors. Licensee MDPI, Basel, Switzerland. This article is an open access article distributed under the terms and conditions of the Creative Commons Attribution (CC BY) license (https:/ / creativecommons.org/licenses/by/ $4.0 /)$.

\begin{abstract}
During the COVID-19 pandemic, campuses are closed, and many schools are forced to transition to online instruction. There are many problems in landscape architecture education during the pandemic such as students' decreased attention, poor self-regulation, low proactivity, and difficulty in grading. In addition, situational effects are required for landscape architecture education, but online education lacks the necessary case scenarios for courses during the pandemic. In order to solve these problems, the present study adopted a more accessible, and interactive spherical video-based immersive virtual reality (SV-IVR) approach, developed a landscape architecture SVIVR learning system, and conducted a quasi-experimental study to examine its effectiveness. The results indicated that the experimental group students showed more positive results in their learning achievements, learning attitudes, and self-regulation than the control group. Besides, it was found that students required more time to develop their self-efficacy and that this system would not have an effect on students' cognitive load.
\end{abstract}

Keywords: spherical video-based immersive virtual reality; landscape architecture education; landscape design; VR-based teaching-learning environments; immersive virtual environments; learning system; COVID-19

\section{Introduction}

With the impact of the COVID-19 pandemic, education systems around the world have encountered huge challenges. Many schools have been forced to cancel in-person classes and shift to online teaching and learning [1]. An increasing number of schools have adopted distance education and are making use of various platforms for teaching activities, for example, video conferencing, emails, and massive open online courses (MOOCs) [2]. Zhu and Liu [2] further indicated that these types of teaching activities mitigate the negative effects of the pandemic to some extent; however, several problems are still found. First, students normally learn at home rather than in a school setting, which leads to the decline of self-regulation for some students. There is even a situation where students open the teacher's live streaming and play with another mobile device at the same time. As a result, students' attention levels are weaker than those in face-to-face classes, which is in line with García-Peñalvo, Corell, Abella-García, and Grande-de-Prado's [3] finding.

In these circumstances, landscape architecture education faces a greater challenge in addition to the above problems. Since landscape architecture education requires exposure to a substantial number of design cases, landscape designs, landscape architecture, and historical remains, situated learning is critical to this area of education. Case studies are extremely important for landscape architecture education. It can provide students with opportunities to be exposed to landscape designs; however, the contexts it can offer in classroom activities are limited [4]. It is evident that with the influence of the pandemic, 
students can only explicate these works through photos or videos. It is truly difficult for students to empathize with the works and enhance their inspiration for creation by only responding to the teacher's demonstration of pictures or videos at the other end of the computer. In the past, when there was no pandemic, the teacher could take students out for field investigations, or students could even experience these places in person. Nonetheless, this became difficult after the outbreak of COVID-19 [5]. Therefore, technology or a method is urgently needed to solve the aforementioned problems at this moment.

The development of science and technology has led to changes and progress in teaching methods. Among these educational technologies, the application of virtual reality (VR) technology in education has brought tremendous progress to situated learning $[6,7]$. With the maturity of VR technology, several experts have started to integrate it into classroom teaching. VR technology has been applied to many disciplines, and its application value and feasibility have also been proved by studies, for example, in STEM education [8], EFL students' English learning [9], geoscience [10], medical education [11], and physics [12]. The adoption of VR in education has brought about enormous changes to teaching and learning in many disciplines. With VR technology, situational effects that are usually difficult to show in the classroom can be well presented. With the raging pandemic, campus closures, and shortcomings in online learning, VR technology has shown its great potential. Especially in landscape architecture education, its prospects for development are promising.

In addition, we have detected that online education faces a few problems during COVID-19 as we mentioned above. VR technology is needed since landscape architecture education in particular requires numerous contexts. However, the production of materials and the preparation of equipment for 3D model-based VR technology are complicated and cumbersome. Thus, it will consume more human and material resources during the implementation and will have higher operational requirements for teachers and students $[7,9,13,14]$. In order to better present the contexts of landscape architecture education, the present study adopted a spherical video-based virtual reality approach. Compared to 3D model-based VR technology, a spherical video-based immersive virtual reality (SV-IVR) learning system is convenient, with simple and intuitive operation. Only a smartphone and a pair of portable cardboard goggles are required to operate the system. No matter whether it is the preparation and creation of materials or the operation for students, SV-IVR can meet the needs of students and teachers and provide educators with a viable alternative [15].

Furthermore, the use of SV-IVR in education is a relatively new research field in educational technology [16]. Currently, there are still relatively few studies using this new SV-IVR in landscape design courses. Therefore, we proposed SV-IVR, and also innovated the instructional design to produce a specifically for landscape architecture education SV-IVR learning system which is a systematic cyclical learning process with level design. This can be considered as an innovation under COVID-19. This is for the field of landscape architecture, because landscape architecture design is different from other proven courses, as it requires more three-dimensional spatial imagination. Among the existing studies on landscape architecture education and VR, most were related to its educational potential [17]. In addition, a majority of studies on the use of VR technology in landscape architecture education also mentioned the disadvantages of 3D model-based VR technology, such as its complexity, high cost, and time-consuming nature [18,19]. It is believed that VR technology should be further improved in order to be better applied in courses. As a result, the current study integrated SV-IVR into a landscape architecture history class, which is a relatively new attempt.

In order to assist landscape architecture students in their learning performance, enhance their learning attitudes, and develop their self-regulation during the COVID-19 era, this study developed a landscape architecture SV-IVR learning system based on the SV-IVR approach. A quasi-experimental study was adopted to compare the effect of the SV- 
IVR approach and conventional technology-supported learning approach on a landscape architecture history class. The following research questions were proposed:

(1) Can the SV-IVR learning system enhance students' learning achievements in comparison with the conventional technology-supported learning approach?

(2) Can the SV-IVR learning system enhance students' learning attitudes in comparison with the conventional technology-supported learning approach?

(3) Can the SV-IVR learning system enhance students' self-regulation in comparison with the conventional technology-supported learning approach?

(4) Can the SV-IVR learning system enhance students' self-efficacy in comparison with the conventional technology-supported learning approach?

(5) Can the SV-IVR learning system reduce students' cognitive load in comparison with the conventional technology-supported learning approach?

Based on the research questions, we propose the following hypotheses.

(1) The SV-IVR learning system can enhance students' learning achievements in landscape architecture class.

(2) The SV-IVR learning system can enhance students' learning attitudes in landscape architecture class.

(3) The SV-IVR learning system can enhance students' self-regulation in land-scape architecture class.

(4) The SV-IVR learning system can enhance students' self-efficacy in landscape architecture class.

(5) The SV-IVR learning system will not increase students' cognitive load in landscape architecture class.

In order to better understand the proposed hypotheses, the following literature review and other content are presented.

\section{Literature Review}

\subsection{Virtual Reality and SV-IVR}

VR is a new media technology that brings immersion and presence through threedimensional (3D) simulations of real scenes or recordings of real environments. It has an interactive and spherical presentation that makes the experiencers feel as if they are present in a real scene $[7,9,20]$. VR can be divided into three categories on the basis of previous research: desktop VR (low-immersive VR desktop environments), which makes use of computer 3D modeling to build a 3D landscape, and which, users can view and experience through a computer, mobile phone, tablet computer, and so on; cave-based VR, which provides a panoramic sensory experience in a confined space; and the fully immersive VR system, which achieves immersion through VR equipment [7,9,21,22]. The rapid development of VR technology has also resulted in numerous possibilities for classroom teaching. Although many researchers have reported the positive influences of VR on students' learning performance, and have noticed its potential for designing education, they have also pointed out the challenges of applying it in classrooms. VR is not always shown to be the most effective way to impact perception, depending on the metric used, as previous research [23] points out. It may also cause vertigo which could be due to the physiological conditions of individual students, as indicated by several researchers [24,25]. Furthermore, many schools or learners have discovered that the application of VR is hindered by its high cost and difficulty of implementation [26]. Moreover, teachers also have difficulties developing VR teaching materials. Hence, seeking an accessible type of VR is critical [19].

In recent years, a growing number of SVVR systems or resources have been in the development process [13]; among them, SV-IVR can meet the needs of the school environment. It is more convenient, and it only needs to use a panoramic camera such as Insta360 for material production [27]. It is a VR technology with spherical videos, which allows viewers to continuously pan and tilt within a circle. Immersive videos allow viewers to 
freely browse in 360 degrees, and they can control the content and angle they want [9]. Additionally, SV-IVR solves the problem of VR that relies too much on 3D modeling. Compared to 3D model-based VR technology, SV-IVR saves a great deal of time. With the advancements of technology, the development of mobile applications, and the popularity of 360-degree cameras, the public can now create their own 360-degree spherical images or videos quickly, freely, and conveniently [7]. For landscape architecture education teachers, this is a simpler and more convenient way to develop VR materials, which is easy to promote [28]. Therefore, the convenience, interactivity, and situational experience of SV-IVR demonstrate its vast potential in the field of education [27].

The effects of SV-IVR on teaching have been verified by many researchers, and it has been adopted in an expanding range of disciplines and the field of education. Its emergence provides teachers with a new teaching concept and approach [28]. For example, Yang, Chen, Zheng, and Hwang [29] adopted the SV-IVR experience learning system in Chinese writing classes in order to enhance students' writing performance and interest. The findings revealed that students using the SV-IVR approach attained higher grades. Hence, the study implied that it is worth using this low-tech experiential learning approach in other courses. Besides, in terms of teachers' training on classroom misbehavior management, Ye et al. [27] used SV-IVR to develop a training system of classroom behavior management (TrainCM2). They believed that the development cost of a 3D model-based VR scene was too high from the perspective of time, so the use of SV-IVR solved this problem well. Their study regarded SV-IVR as an innovative technology with great educational potential. Besides, with the various inconveniences resulting from COVID-19, SV-IVR has more advantages in terms of technology, time, and cost. Unfortunately, although many classes have succeeded in using SV-IVR, this has not inspired researchers to integrate this technology into landscape architecture classes. Therefore, we attempted to combine landscape architecture classes with the SV-IVR approach and verify the relationship between the two.

\subsection{Immersion}

Immersive technologies such as VR blur the boundaries between the real world and the virtual world, enabling users to experience a sense of immersion [30,31]. Immersion is a sensory experience, as described earlier [32]. In a review of the literature [30], the authors concluded that the use of immersive technology enhances students' learning experiences, fosters collaborative engagement, and can increase creativity and engagement; therefore, it is beneficial for students to add immersive experiences to the teaching process as appropriate. Moreover, in another study [33], the authors noted that multisensory coherent collaboration and cues such as visual, auditory, and tactile cues can enhance this immersion. At the same time, well-designed VR materials and content would contribute to the immersion process. A prior study [34] also concluded that one of the important features of VR is immersion, which enhances the situated experience of users.

For landscape architecture learning, situated experience is extremely important; it requires more three-dimensional spatial imagination, so VR for landscape architecture design has great potential for development [35]. VR technology can bring a better sense of immersion to landscape architecture learning. Therefore, the SV-IVR learning system proposed in this study is designed to enhance the immersion experience of the landscape architecture learning process, and carefully designing the VR learning materials and contents.

Of course, over-emphasis on immersion may also bring negative effects, as a prior study [30] argued that attention should be paid to the negative emotions such as fear and anger brought about by such immersion during the VR experience. At the same time, everyone's senses are different, so this may also have a different impact on immersion. In addition, another study [33] pointed out the discomfort symptoms such as dizziness caused by immersion in VR material. 
Therefore, in our landscape architecture SV-IVR research process, we should not only use immersion well to bring positive effects to landscape architecture SV-IVR learning but also be careful to avoid the negative factors that this may cause.

\subsection{Landscape Architecture Education}

Landscape architecture education is linked to and inseparable from explicating and analyzing classic landscape designs, landscape architecture, historical remains, and so on. Case studies are necessary for landscape architecture students. In landscape architecture classes, teachers are usually required to present students with various works or cases through pictures or videos to transfer knowledge and skills [18]. However, as time goes by, students increasingly resist this traditional way of appreciation. Moreover, due to insufficient visits and excursions, the effect of traditional landscape education is poor. Students aspire to have a new technology incorporated into the classroom to replace the previous one-way knowledge transfer process $[36,37]$. The new change also requires teachers to continuously improve their technical skills and teaching capacity in order to adapt to the development and changing times and to meet the increasing demands of students regarding classroom technology and environment [38]. Besides, situated learning is fairly important to landscape education. The ways to enable students to more conveniently access classic landscape designs at close range and to feel the enchantment of classic works is a concern of many landscape education teachers, especially for courses such as landscape design that require many 3D visualization effects. In special circumstances, for example, the COVID-19 pandemic, these requirements are even more important, and VR technology can fulfill them well. With VR, students can perceive the details and the whole picture of landscape design works or buildings as if they are experiencing them in person, which is a critical step for landscape education [39]. Steinitz [17] also specified that landscape education must strive to keep up with the changing times. Teachers must be good at using new technologies and new materials to teach landscape design. The development of VR also brings a great deal of enlightenment to landscape education. Greinert and Mrówczyńska's [36] study indicated that adopting modern educational technology can improve students' ability to solve landscape problems.

Among the few studies related to VR technology and landscape education, Häkkilä et al. [19] incorporated VR technology into different courses in the field of design at the University of Lapland, Finland. Nevertheless, the study pointed out that the lack of VR equipment and the time spent building the VR learning mode would hinder the adoption and development of the technology in design education. Since common classrooms would not be equipped with professional and expensive VR equipment, it became a problem to incorporate VR into landscape design education. Preliminary preparations required a series of complicated procedures such as designing 3D models, modeling, rendering and importing. This kind of work is a heavy burden for teachers in landscape education, which would also lead to setbacks in the research of VR technology and landscape education. Hence, the study called for future researchers to develop a more convenient, cheaper, and more accessible form of VR technology, which can provide more space for developing and introducing VR technology in design education. The present study is a response to this appeal; rather than 3D model-based VR technology, we actively developed and incorporated an SV-IVR learning system into landscape education and examined its effects.

By analyzing the studies of VR technology and landscape education, we found that most of the studies adopted 3D model-based VR technology. For instance, Carbonell et al. [18] conducted an experiment with the 3D model-based heavy VR equipment but did not receive good experimental results, which might have been caused by the equipment. Chang, Chou, Chuang, Li, and Tsai [40] also developed a new VR technology and carried out an experiment. They put in a great deal of time and effort but still failed to use it in landscape education. This type of VR technology is mostly made by computer 3D modeling, and it is digital and virtual, which is very different from SV-IVR. SV-IVR presents the effects by taking photos and shooting 360 -degree videos, so it can provide an immersive 
and lifelike experience [38]. SV-IVR is also more suitable for landscape education which involves the appreciation of good landscape designs, geovisualization immersive virtual environments, or virtual field trips and case studies. As a result, in order to better use VR technology in landscape education, the SV-IVR approach may be a good choice. There is still a lack of research on incorporating the SV-IVR technology into classrooms in landscape education, which may be an innovation for landscape education or the SV-IVR technology.

\section{Materials and Methods}

In order to examine the effects of the landscape architecture SV-IVR learning system on landscape education, a quasi-experimental study was conducted in a landscape architecture history course. The quasi-experimental design is a more scientific approach to research because it explores the causal relationships between independent and dependent variables in a well-controlled context. For some experimental studies that are not easy to conduct, the quasi-experimental research method can be adopted to design some control methods to minimize the potential factors affecting the validity of the study [41]. As the basic course in landscape education, the importance of a landscape architecture history curriculum is self-evident. The present study aimed to explore the effects of the SV-IVR learning system on students' learning achievements, learning attitudes, self-regulation, self-efficacy, and cognitive load in landscape education.

The analysis of covariance (ANCOVA) was used in this study to perform the statistical analysis of the data. ANCOVA treated the pre-test score as a predictive variable (or control variable) of the post-test score, and then detected whether the adjusted post-test score had intergroup differences after the adjustment of the pre-test score [42].

\subsection{Participants}

A total of 140 first-year students majoring in landscape design at a university in China were recruited for this study, with 70 students (39 females and 31 males) randomly chosen as the experimental group and 70 students ( 41 females and 29 males) as the control group. Their average age was 20 years. The experimental group adopted the SV-IVR learning system in the learning process while the control group adopted the conventional technology-supported learning approach. All of the students were taught by the same professor who had more than eight years of teaching experience in landscape architecture history. Due to the pandemic, Google Cardboard was mailed to each student in the experimental group one week before the experiment. The teacher live-streamed the meetings for students to learn at their homes. All students knew about, had seen, or had been exposed to VR, but did not have experience of VR learning and had no prior knowledge of SV-IVR.

\subsection{Measurement Scale Instruments (Tests and Questionnaires)}

The measurement scale instruments adopted in the present study included the pretest, post-test, learning attitudes questionnaire, self-regulation questionnaire, self-efficacy questionnaire, and cognitive load questionnaire. For the Likert 5-point scale in this survey, instead of using the "strongly agree to strongly disagree" description, we used a more precise numerical description, using a numerical scale from 1 to 5 to indicate the degree of approval (See Appendix A).

A pre-test and a post-test were developed by three teachers who had taught landscape architecture education for many years. The pre-test aimed to evaluate students' prior knowledge. It consisted of 10 multiple-choice items and 10 true/false items, with a perfect score of 100. The post-test was designed to evaluate students' concepts and knowledge in the landscape architecture history course. The test also included 10 multiple-choice items and 10 true/false items, with a perfect score of 100. In addition, we consulted two experts in landscape architecture history to verify that the tests were adequate to assess students' learning achievements for the unit.

The learning attitude questionnaire was adapted from the measure developed by Hwang, Yang, and Wang [43]. It consisted of seven items with a 5-point Likert scale. 
Examples of questions include: "I would like to learn more and observe more in the course" and "I think learning landscape architecture is interesting and valuable".

The self-regulation questionnaire with a total of 24 items was modified from Barnard et al. [44]. It was further divided into six dimensions with a 5-point Likert scale: environment structuring (4 items), goal setting (5 items), task strategies (4 items), time management (3 items), help seeking (4 items), and self-evaluation (4 items). Examples of questions include: "I will summarize what I have learned in the course to see how well I understand the content" and "I will not reduce the quality of my learning because it is a landscape architecture course".

The self-efficacy questionnaire was revised from Wang and Hwang [45]. It consisted of eight items with a 5-point Likert scale. Examples of questions include: "I believe I will receive an excellent grade in this class" and "I'm confident I can do an excellent job on the assignments and tests in this course".

The cognitive load questionnaire was adapted from the measure developed by Hwang et al. [43]. It consisted of eight items with a 7-point Likert scale and was divided into two dimensions. Examples of questions include: "The learning content in this learning activity was difficult for me" and "During the learning activity, the way of instruction or learning content presentation caused me a lot of mental effort".

\subsection{The Landscape Architecture SV-IVR Learning System}

In order to successfully employ SV-IVR in landscape education for students to learn the landscape architecture history curriculum, the current study developed a landscape architecture SV-IVR learning system, as shown in Figure 1. This study made use of the EduVenture VR platform (http:/ / vr.ev-cuhk.net/, accessed on 10 May 2021) developed by a university in Hong Kong as the development tool (Jong et al. [15]). Through this platform, we created a new stage to develop the SV-IVR system; the instructions of the buttons on the platform were easy to follow. The teachers created the learning materials on the EduVenture VR platform on the computer, and then the students could learn through the EduVenture VR app and Google Cardboard. The system consists of three modules: the learning material editing module, the database module, and the SV-IVR learning module. In the editing module, the teacher imported and edited the 360-degree panoramic photos and videos obtained through a panoramic camera (Insta 360) or other sources in advance (i.e., download from UtoVR: https: / /www.utovr.com/, accessed on 10 May 2021). According to the teaching activities, the teacher was able to adequately arrange these materials and design the whole learning process through the editing stage in EduVenture VR. In addition, based on the requirements of a landscape architecture history course, the teacher could modify and design materials and set up quiz questions and interactive sessions. The interface of the SV-IVR learning material editing module for the teacher is demonstrated in Figure 2. Through it, teachers could import teaching audio and questions on panoramic pictures or videos, set interactive sessions, and so on.
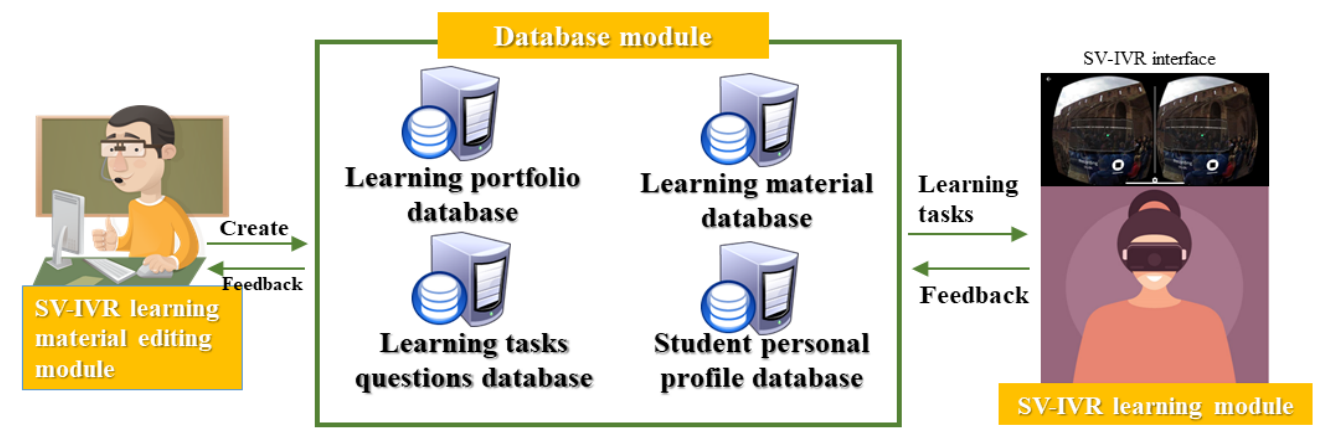

Figure 1. System structure of the landscape architecture SV-IVR learning system. 


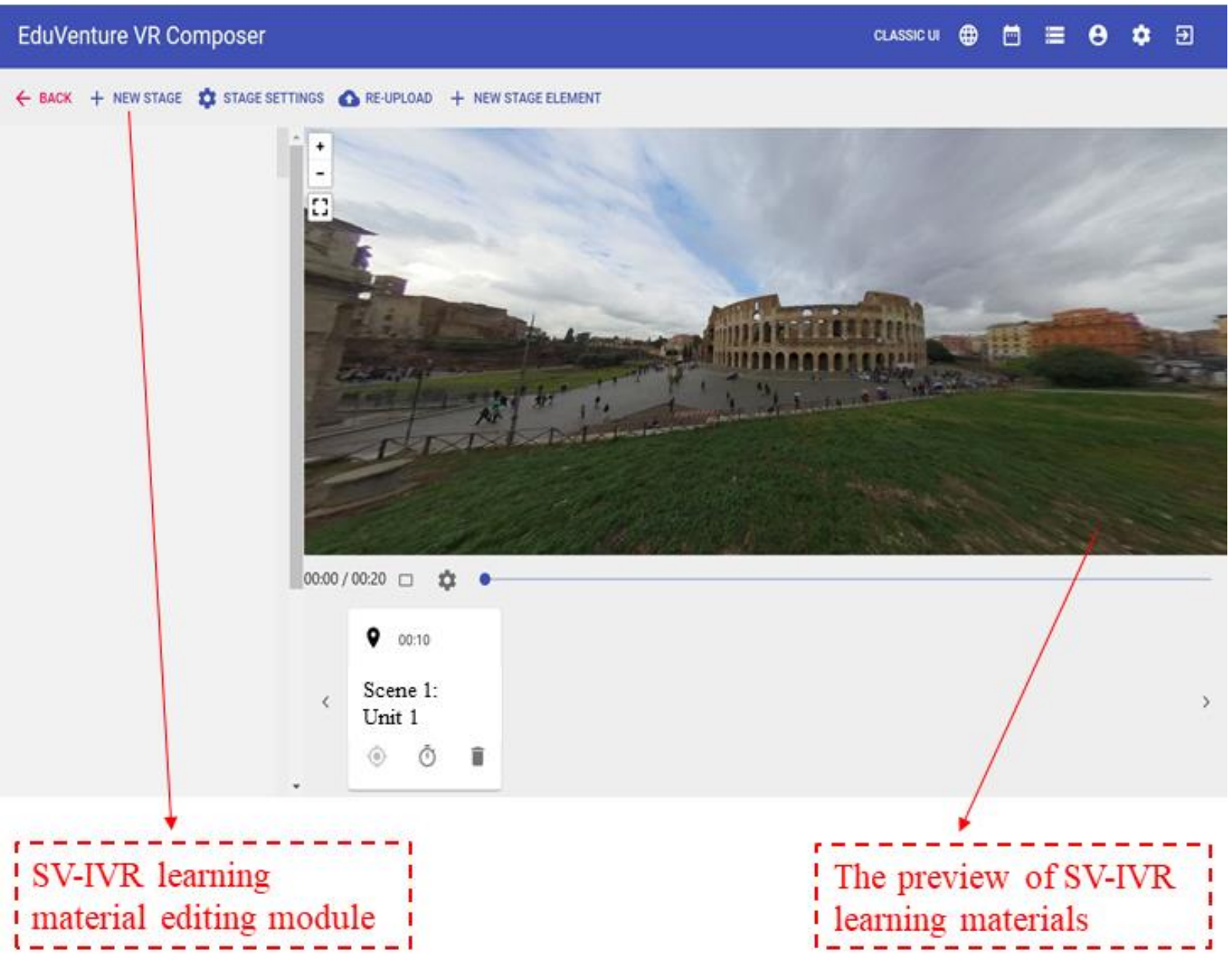

Figure 2. Interface of the SV-IVR learning material editing module.

As for the database module, it is a web-based cloud database (http: / / vrhost.ev-cuhk. net/locale/stage, accessed on 1 April 2021; it requires a password) which contains the data of the four aspects shown in Figure 1. Students' personal information, grades, and recorded data were stored in this database. Teachers could check students' learning performance by accessing the database. To carry out the teaching smoothly, the teacher could check, modify, and understand students' latest learning status and situation through the system at any time.

In the SV-IVR learning module, students conducted SV-IVR learning with mobile phones and Google Cardboard. They entered the virtual environment according to the course arrangement where they immersed themselves in the landscape design works or architecture and followed the system instructions to learn, answer questions, and complete designated learning tasks (see Figure 3). 


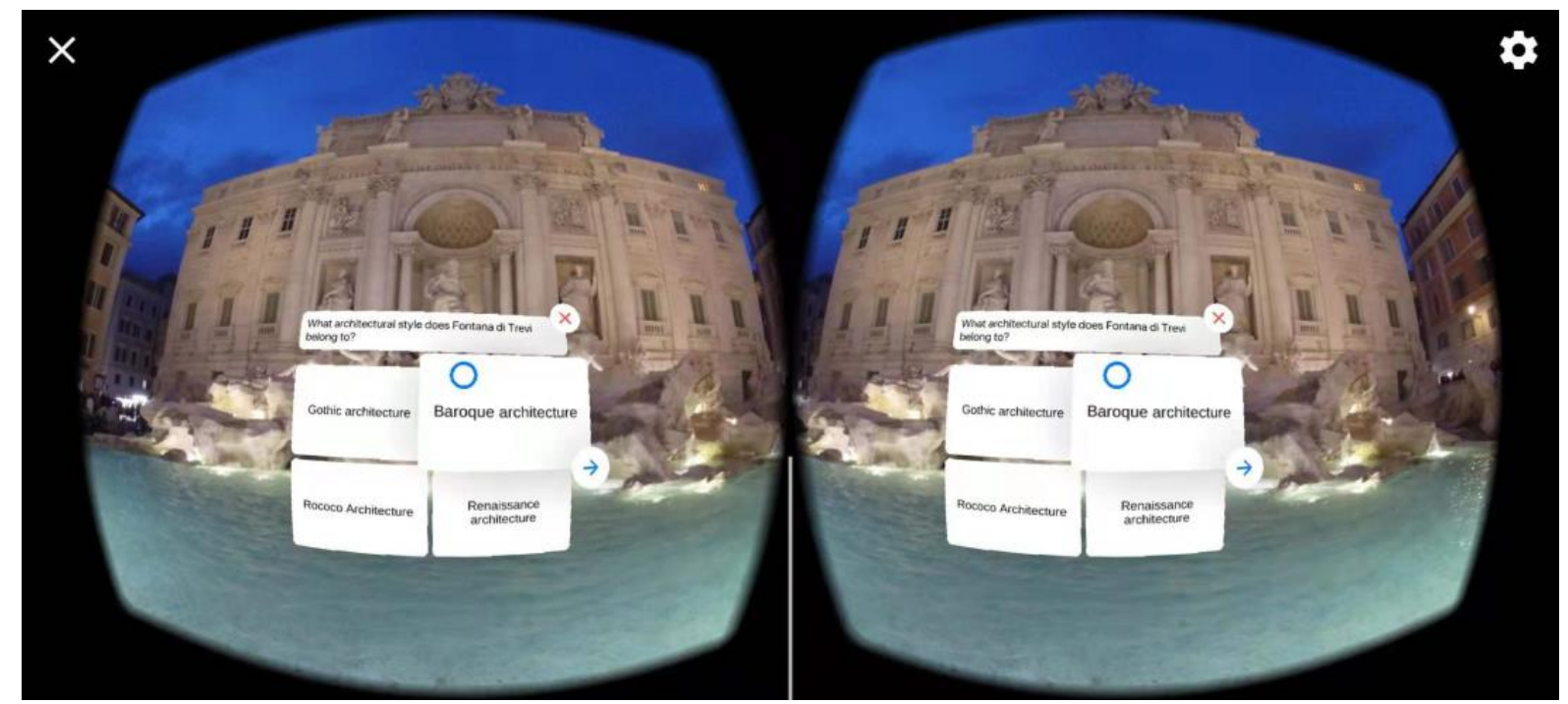

Figure 3. A screenshot of the SV-IVR learning system.

In the landscape architecture SV-IVR learning system, students experienced a systematic cyclical learning process with level design. According to the learning content designed by the teacher, students entered the scenes of each unit and followed the audio instructions (AI text-to-speech conversion by IFLYTEK) from the background to experience and learn in the system. For instance, in the scenes of Roman landscape architecture, students visited Roman architecture and landscapes as if they were standing in front of these buildings and enjoyed the enchantment of the landscape designs with the audio introduction of Roman landscape architecture. After students visited the Roman landscape architecture, within a limited period of time, the system automatically popped up the quiz questions about the landscape design. Students were required to answer the questions according to what they had learned within a limited time. Only when they answered all the questions correctly, they could proceed to the next unit. Otherwise, they had to study the unit again until they obtained the correct answers. Figure 4 illustrates the interface when students answer the quiz question. Figure 5 shows the interface for the selection of units. This cyclical learning process (see Figure 6) can ensure that students learn each unit seriously. Only by carefully listening and visiting, students can receive the corresponding knowledge to answer the questions and enter the next unit to complete the learning.

The system also provided a number of interactive sessions. The teacher promptly proposed thought-provoking questions, and then guided students to answer them during the learning process. Students were then required to record their answers in the virtual environment and upload them to the back-end database, as shown in Figure 7. Besides, the teacher set up a scavenger hunt during the learning process. When the system introduced the classic landscape designs, it described the appearance of the work, and then guided the students to find it in a hidden location of the virtual scene (see Figure 8). Through this interaction, it was expected to stimulate students' proactivity and activeness, enabling them to obtain multi-level feedback and reflections, and guiding them to carry out high-level thinking. 


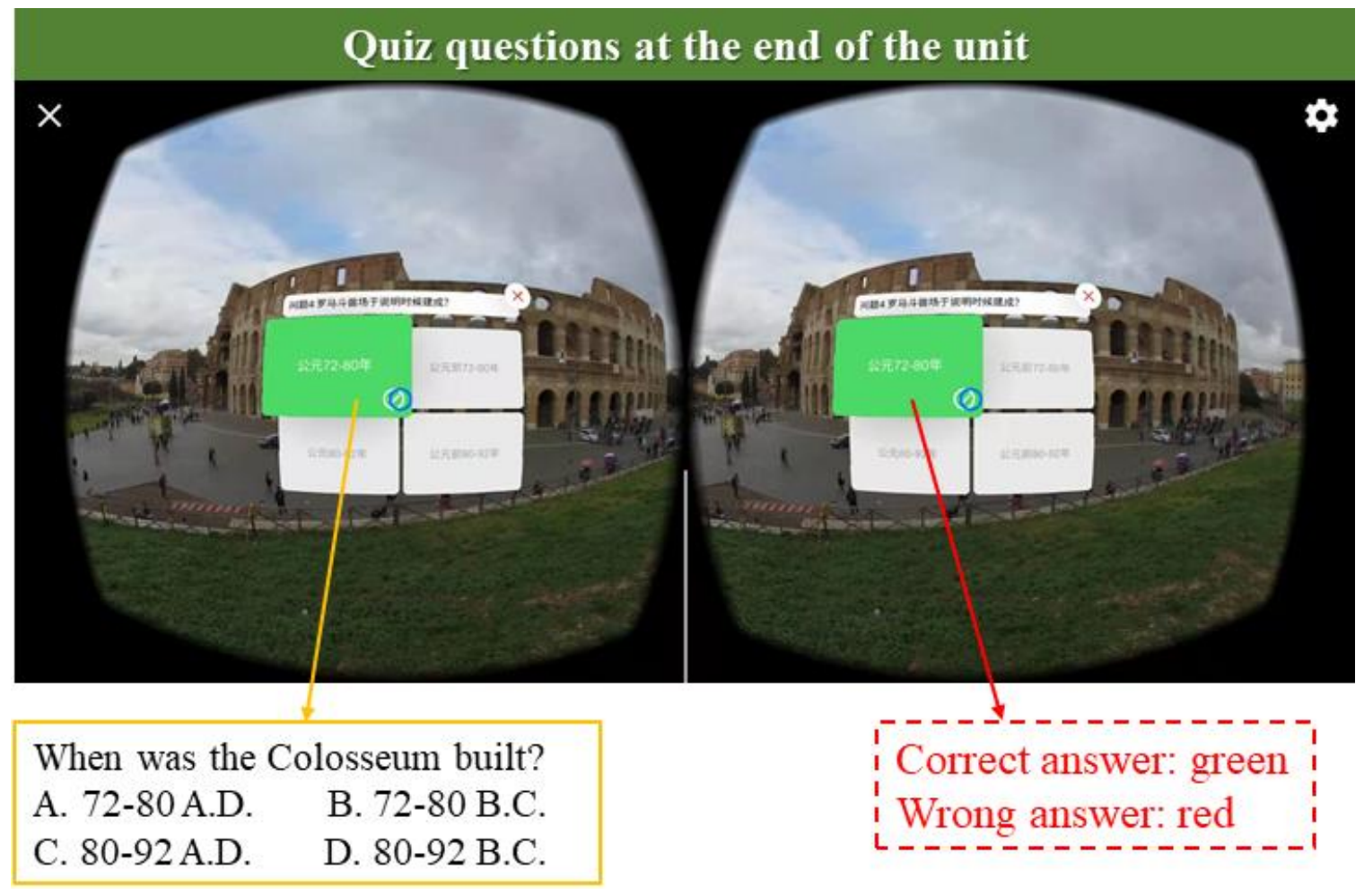

Figure 4. A screenshot of the SV-IVR learning system: quiz questions.

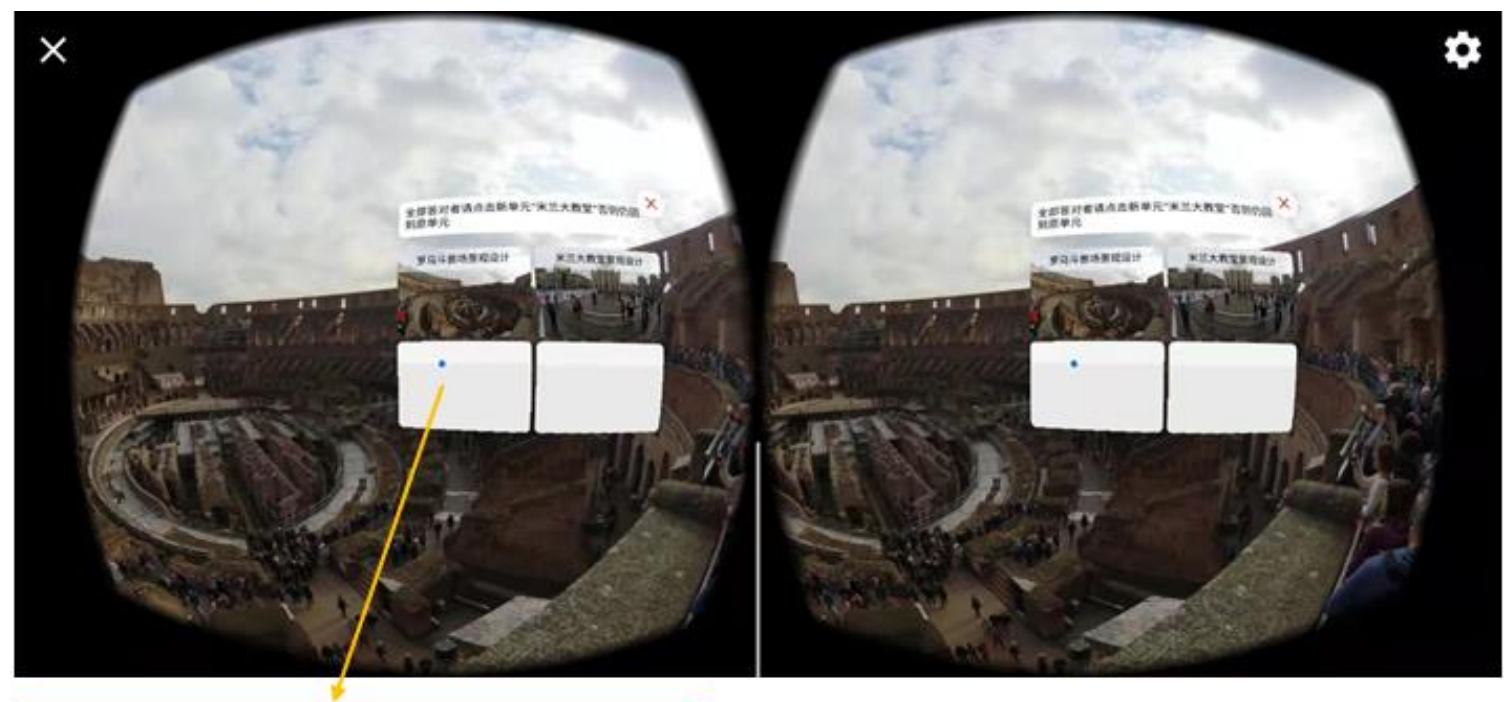

If all the answers are correct, go to the next unit.

If not, study this unit again.

Figure 5. A screenshot of the SV-IVR learning system: go to next unit. 


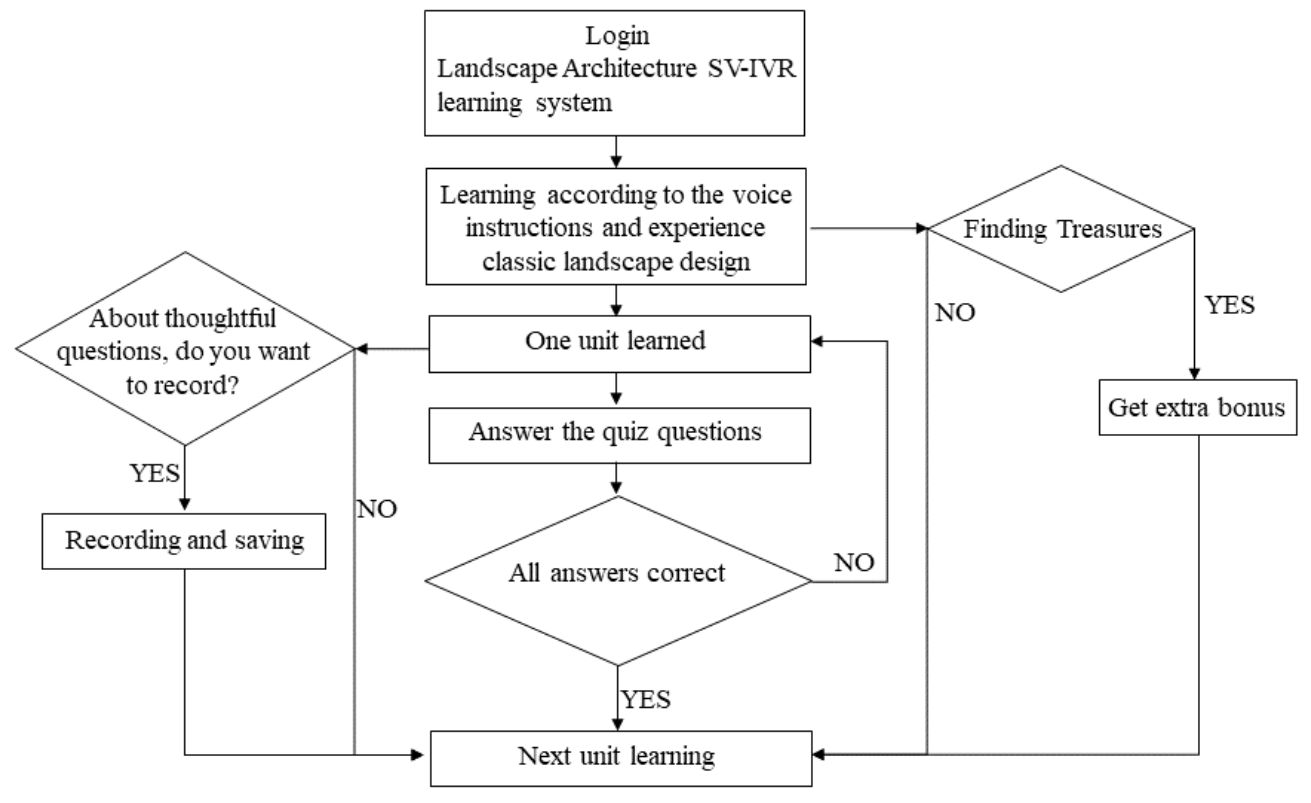

Figure 6. Learning flow chart: a systematic cyclical learning process.

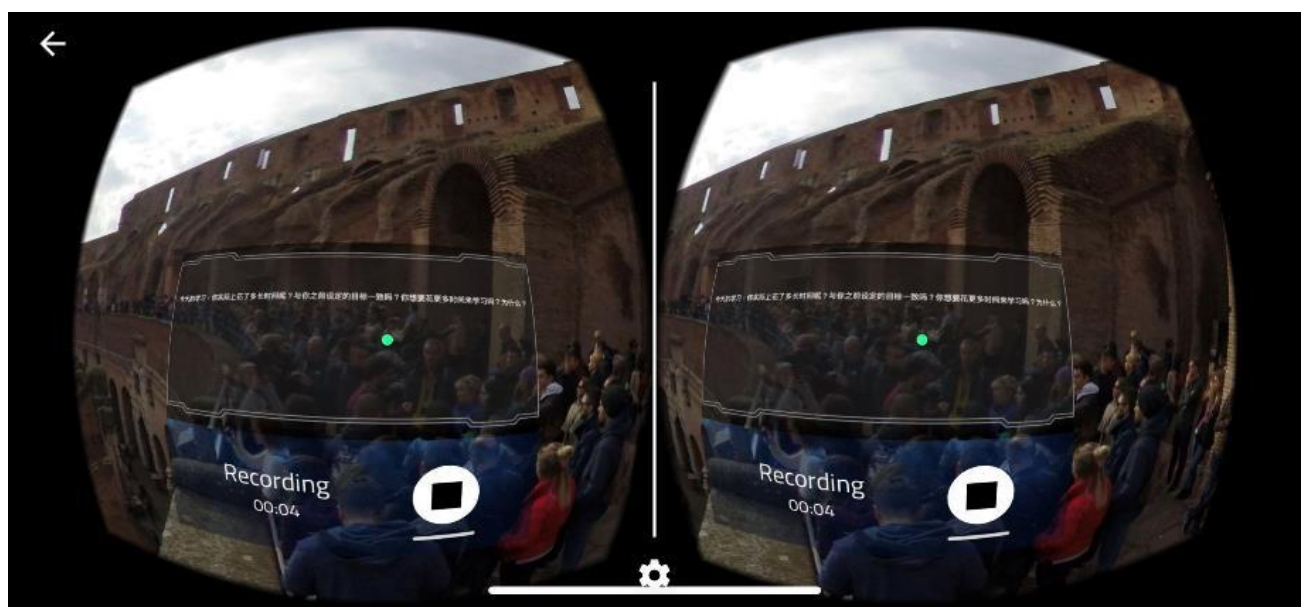

Figure 7. A screenshot of the SV-IVR learning system: record answers.

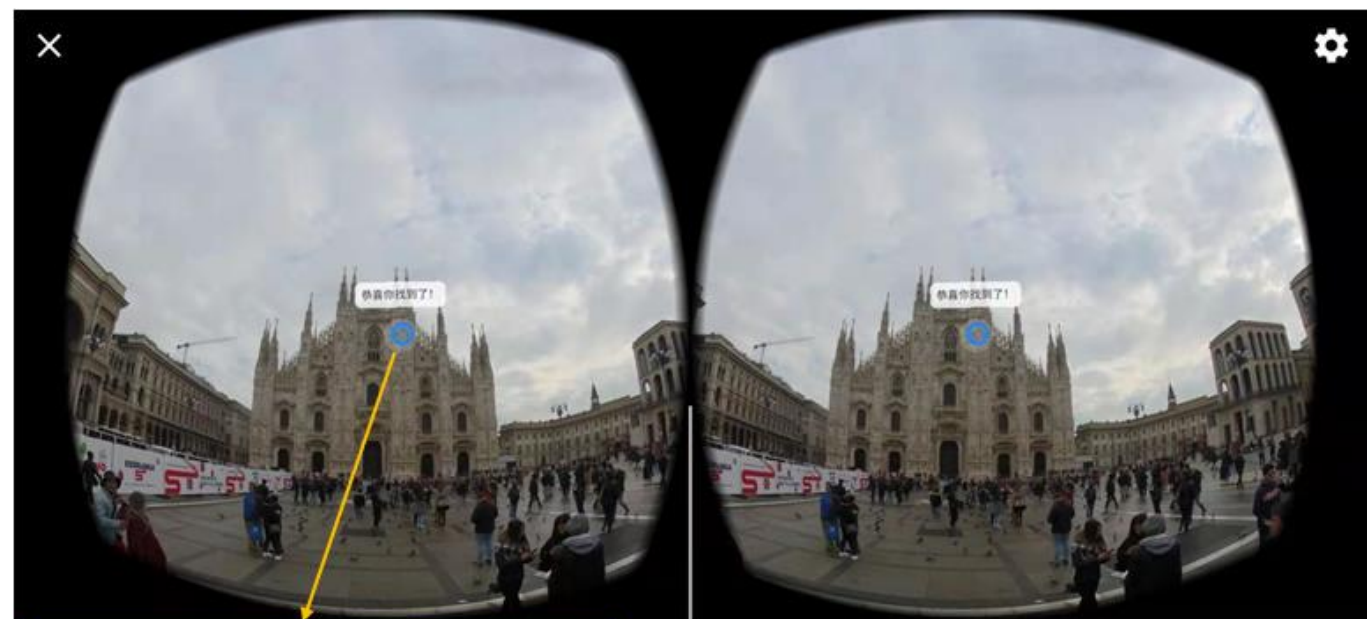

Congratulations! You found it.

Figure 8. A screenshot of the SV-IVR learning system: scavenger hunt. 
This immersive, interactive, multi-level, and cyclical learning process was expected to enhance students' deep motive, reduce their surface strategies, and decrease the ineffective learning in the landscape education course. This learning process also aimed to improve upon the one-way knowledge transfer from teachers in the past. In the context of COVID-19, the combination of the problems faced by landscape architecture courses, and the fact that there is little research on SV-IVR in landscape architecture studies, means that this approach can be considered as an innovation. We hope it will be helpful for landscape design education.

\subsection{Experimental Procedure}

Figure 9 shows the experimental process. A total of 140 students were randomly divided into two groups. At the beginning of the experiment, the students in the two groups were required to take the pre-test and complete the pre-questionnaires of selfregulation, learning attitudes, and self-efficacy, which took $50 \mathrm{~min}$. It is worth noting that students did not know which group they were assigned to before the experiment and, in order to maintain the accuracy of the experiment, we did not tell students that there were two learning styles before the experiment. Furthermore, the two groups were separated so that the students did not know how the class would be conducted until it started.

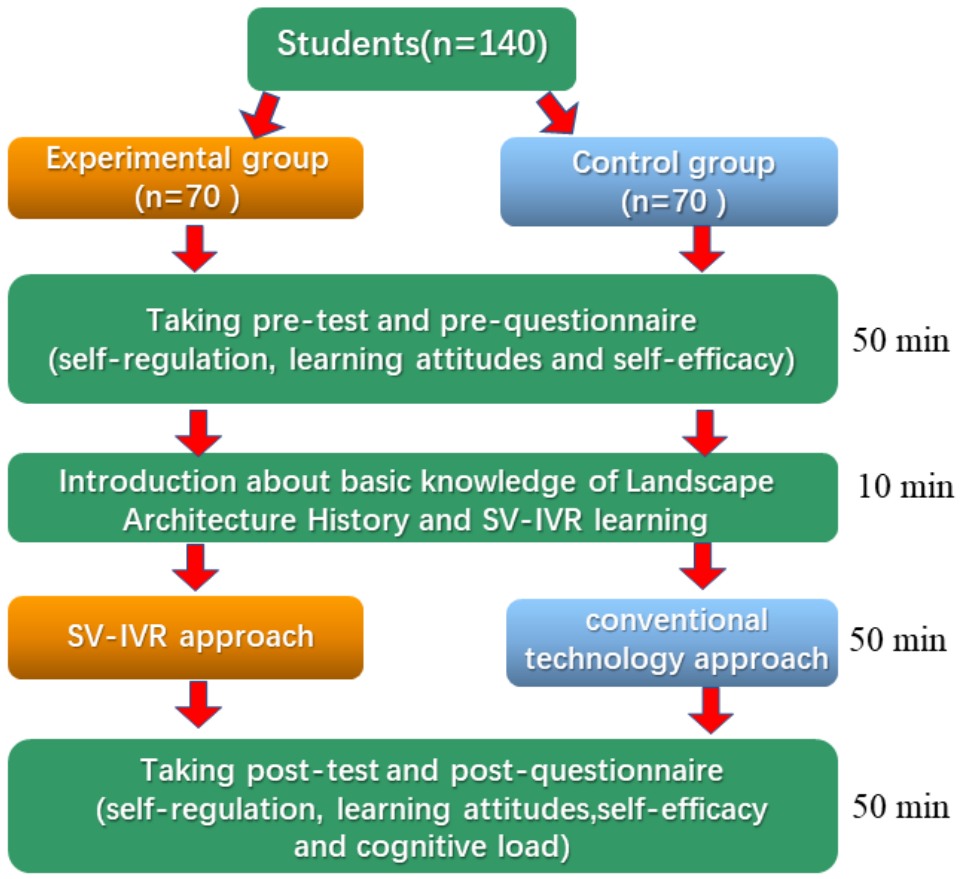

Figure 9. The experimental process.

Moreover, the teacher live-streamed and briefly introduced the course, the SV-IVR learning system, the operational guidance, the precautions, and so on. During the experiment, the experimental group adopted the SV-IVR approach and learned with a Google Cardboard in the landscape architecture SV-IVR learning system. After entering the learning system, the SV-IVR contexts were presented through a smartphone. On the other hand, the control group learned with the conventional technology-supported learning approach which refers to the traditional multimedia approach to class, such as PPT presentations, videos, pictures, etc., presented through a computer screen. A 50-min online instruction session was given by the teacher. After the learning activity, all students took the post-test and completed the questionnaires. The time required for each segment is also shown in Figure 9. 


\section{Results}

\subsection{Test and Questionnaire Results}

The reliability of the test and questionnaires were verified using Cronbach's alpha. The scale for the interpretation of Cronbach's alpha values, according to George and Mallery [45] is: $>0.9$ excellent; $>0.8$ good; 0.7 acceptable; 0.6 questionable; and $>0.5$ poor. The reliability of the results obtained in the present research is good according to this scale [35], as shown in Table 1.

Table 1. The Cronbach's alpha results of test and questionnaires.

\begin{tabular}{lcccccc}
\hline & Pre-Test & Post-Test & $\begin{array}{c}\text { Learning } \\
\text { Attitude }\end{array}$ & $\begin{array}{c}\text { Self- } \\
\text { Regulation }\end{array}$ & $\begin{array}{c}\text { Self- } \\
\text { Efficacy }\end{array}$ & $\begin{array}{c}\text { Cognitive } \\
\text { Load }\end{array}$ \\
\hline $\begin{array}{c}\text { Cronbach's } \\
\text { alpha }\end{array}$ & 0.88 & 0.90 & 0.83 & 0.92 & 0.92 & 0.96 \\
\hline
\end{tabular}

The Cronbach's alpha values of the pre-test and post-test were 0.88 and 0.90 , respectively, showing acceptable internal consistency (Cortina, 1993) [42].

The Cronbach's alpha value of the learning attitude questionnaire was 0.83 .

The self-regulation questionnaire's overall Cronbach's alpha value was 0.92 , and the Cronbach's alpha values of the six dimensions were $0.95,0.92,0.93,0.87,0.96$, and 0.94 , respectively.

The Cronbach's alpha value of the self-efficacy questionnaire was 0.92 , and that of the cognitive load questionnaire was 0.96 .

This means that the reliability of all of the questionnaires was good, and we could use them to conduct the survey.

\subsection{Analysis of Learning Achievements}

To explore the effectiveness of the proposed learning approach on students' learning achievement, ANCOVA was used to exclude the difference between the prior knowledge of the two groups.

The Shapiro-Wilk test was applied to calculate the normality of the data obtained in the study. The result of this test was $0.97(p=0.23)$, implying that the data exhibited a normal distribution. Moreover, Levene's test for determining homogeneity of variance was met $(F=3.11, p>0.05)$, showing that the assumption is tenable and that there was no significant difference in the variance of the two groups. In addition, the assumption of the homogeneity of regression slopes was verified, indicating that one-way ANCOVA could be performed $(F=0.26, p>0.05)$.

Table 2 shows the ANCOVA results of the learning achievements. The adjusted means and standard error were 74.71 and 3.45 for the experimental group, and 65.9 and 3.59 for the control group. According to the result, there was a significant difference between the post-test scores of the two groups $(F=10.84, p<0.05)$. The experimental group attained significantly higher scores on the post-test than the control group, suggesting that students adopting the SV-IVR learning system had significantly better learning achievements than those adopting the conventional technology-supported learning approach. Moreover, the effect size $\left(\eta^{2}\right)$ of the learning achievements was 0.62 , implying a small to medium effect size (Cohen, 2013) [46].

Table 2. The ANCOVA result of learning achievements.

\begin{tabular}{cccccccc}
\hline Group & $\mathbf{N}$ & Mean & SD & Adjusted Mean & SE & $\boldsymbol{F}$ & $\eta^{2}$ \\
\hline Experimental group & 70 & 75.14 & 12.43 & 74.71 & 3.45 & $10.84 *$ & 0.62 \\
Control group & 70 & 65.44 & 19.75 & 65.90 & 3.59 & & \\
$* p<0.05$.
\end{tabular}




\subsection{Analysis of Learning Attitudes}

In order to examine the effectiveness of the proposed learning approach on students' learning attitudes, ANCOVA was performed to exclude the difference between the prequestionnaire of the two groups. Levene's test of determining homogeneity of variance was met $(F=9.16, p>0.05)$, specifying that the assumption is tenable and that there was no significant difference in the variance of the two groups. In addition, the assumption of the homogeneity of regression slopes was verified, showing that one-way ANCOVA could be performed $(F=0.025, p=0.87>0.05)$.

Table 3 shows the ANCOVA results of the learning attitudes. The adjusted means and standard error were 4.23 and 0.10 for the experimental group, and 3.83 and 0.11 for the control group. According to the result, a significant difference in the post-questionnaire scores was found between the two groups $(F=6.79, p<0.05)$, indicating that the SV-IVR learning system can significantly enhance students' learning attitudes compared with the conventional technology-supported learning approach.

Table 3. The ANCOVA result of learning attitudes.

\begin{tabular}{cccccccc}
\hline Group & $\mathbf{N}$ & Mean & SD & Adjusted Mean & SE & $\boldsymbol{F}$ & $\eta^{2}$ \\
\hline Experimental group & 70 & 4.24 & 0.68 & 4.23 & 0.10 & $6.79 *$ & 0.73 \\
Control group & 70 & 3.83 & 0.53 & 3.83 & 0.11 & & \\
\hline
\end{tabular}

\subsection{Analysis of Self-Regulation}

To investigate the effectiveness of the proposed learning approach on students' selfregulation, ANCOVA was conducted to exclude the difference between the pre-questionnaire of the two groups.

The Shapiro-Wilk test was performed to calculate the normality of the data obtained in the study. The result of this test was $0.96(p=0.32)$, showing that the data were normally distributed. Besides, Levene's test of determining homogeneity of variance was met $(F=0.71, p>0.05)$, implying that the assumption is tenable and that no significant difference was found in the variance of the two groups. The assumption of the homogeneity of regression slopes was also verified, showing that one-way ANCOVA could be applied $(F=0.56, p>0.05)$.

Table 4 shows the ANCOVA results of students' self-regulation. The adjusted means and standard error were 3.68 and 0.13 for the experimental group, and 3.10 and 0.12 for the control group. According to the result, there was a significant difference in the postquestionnaire scores between the two groups $(F=9.84, p<0.05)$. The experimental group attained significantly higher scores on the post-questionnaire than the control group, suggesting that the SV-IVR learning system can significantly increase students' self-regulation compared with the conventional technology-supported learning approach.

The current study further conducted analysis on the six dimensions of the postquestionnaire (i.e., goal setting, environment structuring, task strategies, time management, help seeking, and self-evaluation). The results indicated that the experimental group achieved a significantly higher score than the control group on goal setting ( $\mathrm{AM}=3.60$, $\mathrm{SE}=0.08)$, environment structuring $(\mathrm{AM}=3.23, \mathrm{SE}=0.11)$, task strategies $(\mathrm{AM}=3.53$, $\mathrm{SE}=0.15)$, time management $(\mathrm{AM}=4.20, \mathrm{SE}=0.13)$, help seeking $(\mathrm{AM}=4.06, \mathrm{SE}=0.10)$, and self-evaluation $(\mathrm{AM}=3.89, \mathrm{SE}=0.11)$. 
Table 4. The ANCOVA result of self-regulation.

\begin{tabular}{|c|c|c|c|c|c|c|c|c|}
\hline Self-Regulation & Group & $\mathbf{N}$ & Mean & SD & $\begin{array}{l}\text { Adjusted } \\
\text { Mean }\end{array}$ & SE & $F$ & $\eta^{2}$ \\
\hline \multirow[t]{2}{*}{ Goal setting } & $\begin{array}{l}\text { Experimental } \\
\text { group }\end{array}$ & 70 & 3.53 & 0.68 & 3.60 & 0.08 & $8.23 * *$ & 0.76 \\
\hline & Control group & 70 & 3.05 & 0.70 & 3.06 & 0.08 & & \\
\hline \multirow[t]{2}{*}{$\begin{array}{l}\text { Environment } \\
\text { structuring }\end{array}$} & $\begin{array}{l}\text { Experimental } \\
\text { group }\end{array}$ & 70 & 3.23 & 0.63 & 3.23 & 0.11 & $6.70 *$ & 0.10 \\
\hline & Control group & 70 & 3.06 & 0.59 & 3.00 & 0.10 & & \\
\hline \multirow[t]{2}{*}{ Task strategies } & $\begin{array}{l}\text { Experimental } \\
\text { group }\end{array}$ & 70 & 3.60 & 0.81 & 3.53 & 0.15 & $7.17^{*}$ & 0.10 \\
\hline & Control group & 70 & 2.91 & 0.92 & 2.97 & 0.14 & & \\
\hline \multirow[t]{2}{*}{$\begin{array}{c}\text { Time } \\
\text { management }\end{array}$} & $\begin{array}{l}\text { Experimental } \\
\text { group }\end{array}$ & 70 & 4.25 & 0.68 & 4.20 & 0.13 & $8.40 * *$ & 0.12 \\
\hline & Control group & 70 & 3.65 & 0.79 & 3.69 & 0.12 & & \\
\hline \multirow[t]{2}{*}{ Help seeking } & $\begin{array}{l}\text { Experimental } \\
\text { group }\end{array}$ & 70 & 4.12 & 0.65 & 4.06 & 0.10 & $5.50 *$ & 0.08 \\
\hline & Control group & 70 & 3.67 & 0.64 & 3.73 & 0.10 & & \\
\hline \multirow[t]{2}{*}{ Self-evaluation } & $\begin{array}{l}\text { Experimental } \\
\text { group }\end{array}$ & 70 & 3.89 & 0.68 & 3.89 & 0.11 & $9.41 * *$ & 0.86 \\
\hline & Control group & 70 & 3.39 & 0.64 & 3.40 & 0.11 & & \\
\hline \multirow[t]{2}{*}{ Total } & $\begin{array}{l}\text { Experimental } \\
\text { group }\end{array}$ & 70 & 3.73 & 0.66 & 3.68 & 0.13 & $9.84^{* *}$ & 0.15 \\
\hline & Control group & 70 & 3.06 & 0.71 & 3.10 & 0.12 & & \\
\hline
\end{tabular}

\subsection{Analysis of Self-Efficacy}

The Shapiro-Wilk test was adopted to examine the normality of the data obtained in the study. The result of this test was $0.98(p>0.05)$, suggesting that the data exhibited a normal distribution. In addition, Levene's test of determining homogeneity of variance was met $(F=1.65, p>0.05)$, showing that the assumption is tenable and that no significant difference was found in the variance of the two groups. The assumption of the homogeneity of regression slopes was also confirmed, indicating that one-way ANCOVA could be performed $(F=0.26, p>0.05)$.

Table 5 shows the ANCOVA results of students' self-efficacy. The adjusted means and standard error were 3.28 and 0.12 for the experimental group, and 3.27 and 0.11 for the control group. According to the result, no significant difference in the post-questionnaire scores was found between the two groups $(F=0.01, p>0.05)$, implying that there was no significant difference in the self-efficacy of students adopting the SV-IVR learning system and those adopting the conventional technology-supported learning approach.

Table 5. The ANCOVA result of self-efficacy.

\begin{tabular}{ccccccc}
\hline Group & N & Mean & SD & Adjusted Mean & SE & $\boldsymbol{F}$ \\
\hline Experimental group & 70 & 3.29 & 0.92 & 3.28 & 0.12 & 0.01 \\
Control group & 70 & 3.27 & 0.69 & 3.27 & 0.11 & \\
\hline
\end{tabular}

\subsection{Analysis of Cognitive Load}

A $t$-test was performed to analyze the cognitive load of students adopting the SVIVR learning system and those adopting the conventional technology-supported learning approach. Table 6 shows the $t$-test results of students' cognitive load. The means and standard deviations of the post-questionnaire scores were 3.34 and 1.55 for the experimental group, and 3.28 and 1.25 for the control group. No significant difference was found between the two groups, indicating that there was no difference in students' cognitive load between the SV-IVR learning system and the conventional technology-supported learning approach. 
Table 6. The independent $t$-test analysis of cognitive load.

\begin{tabular}{cccccc}
\hline Cognitive load & Group & N & Mean & SD & $t$ \\
\hline Mental load & Experimental group & 70 & 3.02 & 1.56 & 0.70 \\
& Control group & 70 & 2.97 & 1.34 & \\
Mental effort & Experimental group & 70 & 3.48 & 1.52 & -0.55 \\
& Control group & 70 & 3.40 & 1.43 & \multirow{2}{*}{ Total } \\
& Experimental group & 70 & 3.34 & 1.55 & 0.75 \\
& Control group & 70 & 3.28 & 1.25 & \\
\hline
\end{tabular}

\section{Discussion}

The findings indicated that, compared to the conventional technology-supported learning approach, the landscape architecture SV-IVR learning system can result in better learning achievements, learning attitudes, and self-regulation during the pandemic. However, there were no significant differences in the self-efficacy and cognitive load of the two groups.

The present study aimed to integrate the SV-IVR technology into landscape architecture education in the hope of bringing some new changes for landscape education and to keep using SV-IVR, a convenient VR technology, in the field of education. The SV-IVR tool used in this study overcame the problem of unrealistic VR in the past, as well as the high cost and difficulty of designing teaching materials. Furthermore, employing SV-IVR in landscape education is a comparatively new attempt. The results of the current study also indicated that it has a positive influence on the teaching effects in landscape architecture education. In terms of the SV-IVR technology, its effectiveness has been verified again in a new curriculum.

For learning achievements, the study verified the effectiveness of the proposed landscape architecture SV-IVR learning system. Compared to students adopting the conventional technology-supported learning approach, the experimental group achieved higher scores and better learning performance, indicating that the system is effective in landscape education. Based on SV-IVR, the current study developed this immersive, interactive, multi-level and cyclical game-based learning system. With this system, students can ensure the integrity and completion of their learning. This kind of mechanism with its multi-level design can effectively ensure that students can achieve the learning goals pre-determined by the teacher after completing each small unit. If students do not achieve the goal of a unit, they cannot progress to the next unit. Through immersive learning, students can imperceptibly acquire the learning materials and obtain a higher level of experiential learning. Therefore, it enhances students' comprehension and experience in the course content and inspires their learning motivation, which is in line with Jong et al. [15].

In addition, for learning attitudes, the results implied that the experimental group had better learning attitudes than the control group. With the innovative SV-IVR in landscape education, it is novel and interesting for most landscape architecture students. Thus, it can stimulate students' learning proactivity and motivation well, which improves their learning attitudes. In particular, compared to the boring one-way method of knowledge transfer, this novel VR approach can undoubtedly bring new experience and perception to students, and provide greater potential for teaching and learning in landscape education. The findings are also in line with those of Chen, Chai, Jong, and Jiang [47] and Chen, Hung, and Yeh [48].

Furthermore, for self-regulation, students adopting the landscape architecture SVIVR learning system showed better self-regulation than those adopting the conventional technology-supported learning approach. During the pandemic, due to the different learning environments, some of the students have decreased their concentration levels and cannot pay attention to their learning. This problem has been improved through the SV-IVR learning system. As this system needs students to immerse themselves in the virtual world to carry out the learning process, with the related setting, it can help them carry out learning tasks well and control their self-regulation, which is in accordance with Chen and Hsu [49]. 
According to the findings, with this learning system, there were significant differences in the six dimensions of the self-regulation questionnaire between the two groups, namely goal setting, environment structuring, task strategies, time management, help seeking, and self-evaluation. This also shows that students' abilities in these six dimensions have been improved by learning in the landscape architecture SV-IVR learning system. This system helps students carry out their learning process more consciously, improve their learning behavior, enhance their self-observation, realize their learning objectives, and conduct higher-level thinking and deeper learning. Students can then take more control of their own learning, which is in line with Chen and Hsu [49] and Zimmerman, Schunk, and DiBenedetto [50].

According to the interviews with the students in the experimental group after completion of the experiment, some of them said that they had a clear goal of passing the quiz and moving on to the next unit when they were using the SV-IVR learning system. However, some students said that such goal setting was done with the system rather than as a spontaneous behavior. In terms of the environment, some students said that learning through SV-IVR would make them more determined to find a quiet learning environment to study in, but some students said that there was no difference. These results deserve further investigation and analysis to improve the accuracy of the data. However, in general, there are some differences between the two groups of students.

Lastly, no significant differences in the self-efficacy and cognitive load of the two groups could be found in this study. In terms of self-efficacy, one possible explanation is that a short period of studying may not increase students' self-efficacy. Huang et al. [6] and Yang et al. [29] also implied that students need more time and learning experience to develop their capabilities. All students in the experimental group were exposed to this learning system for the first time, so a 50 min learning experience may not have been sufficient to improve their self-efficacy, and self-efficacy needs to be cultivated. Especially for emerging technology, there is still a great deal of uncertainty; hence, students may spend more time developing their self-efficacy. Such results were also found in Huang's study [8] which showed that the change in students' science self-efficacy was not significant after the VR learning activity. A prior study [51] also found insignificant self-efficacy results, which they believe may be due to environmental and technological reasons. This gives future researchers new ideas that may take longer to explore, for example, by performing an extended experiment to develop students' self-efficacy. Meanwhile, due to the limitations of the experimental method, measurement method, and experiment time, the measurement of self-efficacy may not be as accurate. The relevance of the two learning approaches may be limited, and due to cost constraints, this aspect will be further explored in the future.

On the other hand, there was no significant difference in students' cognitive load, which means that students using the SV-IVR learning system and students using the conventional technology-supported learning approach had the same perception of cognitive load. In other words, students who learned with SV-IVR did not reduce or increase their cognitive load. The results of this study are consistent with the research of many scholars [38,52] and suggest that using the SV-IVR learning system in design education is not troublesome for students and that students can control this system well. Moreover, the experimental group will not have an extra cognitive load when using this system to learn the landscape architecture course. Consequently, this learning system can be adopted by landscape architecture students, which is consistent with Huang and Liaw [52]. Furthermore, according to the students' interview records, most of the students from the two groups expressed similar perspectives and perceptions of the system regarding their cognitive load. This was also in line with a prior study [38] that integrated the two-tier test strategy into VR.

However, we also note that many scholars' VR learning studies have shown changes in cognitive load. For example, a study [53] argued that students with certain learning style preferences must bear a greater cognitive load in VR learning in order to achieve the same learning outcomes as other students. Moreover, in another study [26], students who 
used VR for library guide learning activities developed higher cognitive load and therefore perceived students would work harder. Due to the limitation of the experimental method, measurement method, and experimental time, the cognitive load data in this study may have defects, which will be further investigated in future studies.

\section{Conclusions}

In summary, the major contribution of this study is that, different from previous VR learning, this study selected a more accessible, and more convenient SV-IVR, and then developed a landscape architecture SV-IVR learning system to help the teaching and learning in landscape architecture education. In the field of landscape architecture education, the combination with SV-IVR is still a research gap, so this study also calls for more researchers to examine the relationship between SV-IVR and landscape architecture education in the future. In addition, with the sudden COVID-19 pandemic, campuses are closed, which also inspires the future development of education. Educational technology is a development trend. During the pandemic, there are several problems in landscape education such as students' decreased attention, poor learning effects, low motivation, difficulty in grading, and lack of contexts required for the courses. The learning system developed in this study can solve the abovementioned problems well, and provide effective assistance to landscape architecture education during the pandemic.

In addition, the interactivity of the learning system also helps students learn actively. In the past, VR learning only focused on presenting students with views, but interactive sessions were added to this SV-IVR learning system. Students can candidly control the angle and content they want to see in the system. At the same time, according to the thought-provoking questions raised by the teacher, students can record their answers and upload them to the database. The system also guides students to learn in the learning process with audio instructions from the background and provides feedback and guidance according to the different choices of the students. The setting of some interactive sessions similar to a scavenger hunt also adds a great deal of fun to the learning system; students can also leave messages and feedback in the system, and they can answer questions and take quizzes and an examination, which greatly reduces the possibility of cheating. Teachers can easily grasp students' learning situation from the back-end database. It solves the online education problem of the difficulty of assessing students' learning situation during the COVID-19 pandemic. As a result, this kind of interaction can effectively improve students proactivity and enable them to learn actively, making them actively think, experience, and imagine, gain deeper insights and inspirations, carry out high-level thinking, and ultimately enhance their learning performance. For landscape architecture students, the proposed SV-IVR learning system in this study is feasible and effective. The fact that SV-IVR technology increases students' learning performance has also been proved by many researchers $[27,29]$.

However, the limitations of the present study need to be noted. First of all, future studies can consider conducting a long-term experiment. For example, researchers can conduct the experiment for a semester and verify the sustainability of the experimental results. The stability and sustainability of the research findings are the issues that we need to further explore. Second, it is worth trying to apply SV-IVR to more courses in landscape education. Future studies can conduct teaching experiments to confirm its effects on different courses. Besides, researchers can consider expanding the sample size of the experiment to involve more students and further improve the accuracy of the experimental results. Third, the selection of equipment may influence the experimental results. In this study, some students mentioned that cardboard goggles will be easily damaged. As a result, the effects of different equipment can be considered in future studies. Moreover, novelty is also an issue worthy of our attention. Since the novelty brought by new technologies may affect students' real perceptions, future research should consider how to overcome this problem. Last, factors such as different learning styles, different characteristics, academic 
performance, and gender can also be taken into account to further expand the scope and depth of research.

Author Contributions: Conceptualization, W.-L.W. and Y.H.; methodology, W.-L.W. and Q.-F.Y.; software, Q.-F.Y.; validation, W.-L.W., Y.H. and J.-J.C.; formal analysis, W.-L.W.; investigation, W.-L.W., Q.-F.Y. and J.-J.C.; resources, W.-L.W. and Y.H.; data curation, Q.-F.Y. and J.-J.C.; writing-original draft preparation, W.-L.W.; writing-review and editing, W.-L.W., Y.H. and Q.-F.Y.; visualization, W.-L.W.; supervision, Y.H.; project administration, W.-L.W. and Y.H. All authors have read and agreed to the published version of the manuscript.

Funding: This research received no external funding.

Institutional Review Board Statement: Not applicable.

Informed Consent Statement: Informed consent was obtained from all subjects involved in the study.

Data Availability Statement: The data presented in this study are available on request from the corresponding author. The data are not publicly available due to restrictions, e.g., privacy or ethical.

Acknowledgments: The authors thank Morris Siu-Yung Jong (Associate Professor of the Department of Curriculum and Instruction and the Director of Centre for Learning Sciences and Technologies, at the Chinese University of Hong Kong) for the technical support.

Conflicts of Interest: The authors declare no conflict of interest.

\section{Appendix A}

Questionnaires:

\section{Learning attitude (5-point Likert scale)}

Please cite the following paper if you use this measure:

Hwang, G. J., Yang, L. H., \& Wang, S. Y. (2013), A concept map-embedded educational computer game for improving students' learning performance in natural science courses, Computers \& Education, 69, 121-130.

Attitudes toward learning

(1) I think learning landscape architecture history course is interesting and valuable.

(2) I would like to learn more and observe more in landscape architecture history course.

(3) It is worth learning those things about landscape architecture.

(4) It is important for me to learn the landscape architecture history course well.

(5) It is important to know the landscape architecture history knowledge related to our living environment.

(6) I will actively search for more information and learn about landscape architecture.

(7) It is important for everyone to take landscape architecture history course.

\section{Self-regulation (5-point Likert scale)}

Please cite the following paper if you use this measure:

Barnard, L., Lan, W.Y., To, Y.M., Paton, V.O. \& Lai, S.L. (2009). Measuring selfregulation in online and blended learning environments. The Internet and Higher Education, 12, 1-6.

Goal Setting

(1) In landscape architecture history course, I set standards to be met for the learning tasks.

(2) I set not only long-term goals (one month or one semester) but also short-term goals (one day or one week).

(3) I have high standards for my performance in landscape architecture history course.

(4) In landscape architecture history course, I set goals to help me manage my study time.

(5) I do not lower my expectations for the quality of my learning just because it is a landscape architecture history course.

Environment

(1) I will choose a place to study in order to avoid too many interruptions. 
(2) I will find an environment where I feel comfortable to do my learning activities.

(3) I know where my learning will be most effective.

(4) I choose the least disruptive time for learning.

Assignment Strategies

(1) I will take notes more carefully in this course because it is more important to take notes in landscape architecture history course than in traditional learning.

(2) I will read aloud the learning materials in landscape architecture history course to avoid interruptions in the learning process.

(3) I prepare questions to be asked before entering the chat room or discussion room.

(4) I will try to solve questions other than those specified in landscape architecture history course in order to familiarize myself with the content taught in the course.

Time Management

(1) I will use time for learning activities in the landscape architecture history course other than the designated time, because I know that this course take time.

(2) I will try to schedule the same study periods each day or week, and I will be careful to follow these schedules.

(3) Although I don't have to go to school every day like I used to, I still try to divide my learning time evenly each day.

Asking for help

(1) If I find someone who is familiar with the content of landscape architecture history, I will ask them for help if needed.

(2) I will share problems with my classmates, so I know what problems people are having and how to solve them.

(3) I will discuss with my classmates face-to-face if necessary.

(4) I will continue to get help from the teacher via email.

Self-assessment

(1) I will summarize what I have learned in landscape architecture history course to see how well I understand what I have learned.

(2) I ask myself a lot of questions about the content of landscape architecture history course during the learning process.

(3) In my courses, I discuss with my classmates to see how well I am doing.

(4) I will discuss with my classmates to see how my learning differs from theirs.

\section{Self-efficacy (5-point Likert scale)}

Please cite the following paper if you use this measure:

Wang, S.-L., \& Hwang, G.-J. (2012). The role of collective efficacy, cognitive quality, and task cohesion in computer-supported collaborative learning (CSCL). Computers \& Education, 58 (2), 679-687, https:/ / doi.org/10.1016/j.compedu.2011.09.003, accessed on 10 May 2021.

Self-Efficacy for Learning and Performance

(1) I believe I will receive an excellent grade in landscape architecture history class.

(2) I'm certain I can understand the most difficult material presented in the readings for landscape architecture history.

(3) I'm confident I can understand the basic concepts taught in landscape architecture history.

(4) I'm confident I can understand the most complex material presented by the instructor in landscape architecture history.

(5) I'm confident I can do an excellent job on the assignments and tests in landscape architecture history.

(6) I expect to do well in landscape architecture history.

(7) I'm certain I can master the skills being taught in this class.

(8) Considering the difficulty of landscape architecture history, the teacher, and my skills, I think I will do well in this class. 


\section{Cognitive load (7-point Likert scale)}

Please cite the following paper if you use this measure:

Hwang, G. J., Yang, L. H., \& Wang, S. Y. (2013), A concept map-embedded educational computer game for improving students' learning performance in natural science courses, Computers \& Education, 69, 121-130.

Mental load

(1) The learning content in this learning activity was difficult for me.

(2) I had to put a lot of effort into answering the questions in this learning activity.

(3) It was troublesome for me to answer the questions in this learning activity.

(4) I felt frustrated answering the questions in this learning activity.

(5) I did not have enough time to answer the questions in this learning activity. Mental effort

(6) During the learning activity, the way of instruction or learning content presentation caused me a lot of mental effort.

(7) I need to put lots of effort into completing the learning tasks or achieving the learning objectives in this learning activity.

(8) The instructional way in the learning activity was difficult to follow and understand.

\section{References}

1. Daniel, J. Education and the COVID-19 pandemic. Prospects 2020, 49, 91-96. [CrossRef]

2. Zhu, X.; Liu, J. Education in and after Covid-19: Immediate responses and long-term visions. Postdigital Sci. Educ. 2020, 2, 695-699. [CrossRef]

3. García-Peñalvo, F.J.; Corell, A.; Abella, V.; Grande-de-Prado, M. Recommendations for Mandatory Online Assessment in Higher Education During the COVID-19 Pandemic, in Radical Solutions for Education in a Crisis Context; Springer: Berlin/Heidelberg, Germany, 2021; pp. 85-98. [CrossRef]

4. Wu, W.; Hsu, Y.; Chen, J. The Influence of Virtual Reality Learning System on the Learning Attitudes of Design History. In International Conference on Kansei Engineering \& Emotion Research; Springer: Berlin/Heidelberg, Germany, 2020. [CrossRef]

5. Ahmad, L.; Sosa, M.; Musfy, K. Interior Design Teaching Methodology during the Global COVID-19 Pandemic. Interiority 2020, 3 , 163-184. [CrossRef]

6. Huang, H.L.; Hwang, G.J.; Chang, C.Y. Learning to be a writer: A spherical video-based virtual reality approach to supporting descriptive article writing in high school Chinese courses. Br. J. Educ. Technol. 2020, 51, 1386-1405. [CrossRef]

7. Wu, W.L.; Hsu, Y.; Yang, Q.F.; Chen, J.J.; Jong, M.S.Y. Effects of the self-regulated strategy within the context of spherical video-based virtual reality on students' learning performances in an art history class. Interact. Learn. Environ. 2021, 1-24. [CrossRef]

8. Huang, W. Examining the impact of head-mounted display virtual reality on the science self-efficacy of high schoolers. Interact. Learn. Environ. 2019, 1-13. [CrossRef]

9. Chien, S.-Y.; Hwang, G.-J.; Jong, M.S.-Y. Effects of peer assessment within the context of spherical video-based virtual reality on EFL students' English-Speaking performance and learning perceptions. Comput. Educ. 2020, 146, 103751. [CrossRef]

10. Chang, S.-C.; Hsu, T.-C.; Jong, M.S.-Y. Integration of the peer assessment approach with a virtual reality design system for learning earth science. Comput. Educ. 2020, 146, 103758. [CrossRef]

11. Javaid, M.; Haleem, A. Virtual reality applications toward medical field. Clin. Epidemiol. Glob. Health 2020, 8, 600-605. [CrossRef]

12. Cai, S.; Liu, C.; Wang, T.; Liu, E.; Liang, J.C. Effects of learning physics using Augmented Reality on students' self-efficacy and conceptions of learning. Br. J. Educ. Technol. 2021, 52, 235-251. [CrossRef]

13. Geng, J.; Jong, M.S.Y.; Luk, E.; Jiang, Y. Comparative study on the pedagogical use of interactive spherical video-based virtual reality: The EduVenture-VR experience. In Proceedings of the 2018 International Symposium on Educational Technology (ISET), Osaka, Japan, 31 July-2 August 2018; pp. 261-263. [CrossRef]

14. Chang, S.C.; Hsu, T.C.; Chen, Y.N.; Jong, M.S.Y. The effects of spherical video-based virtual reality implementation on students' natural science learning effectiveness. Interact. Learn. Environ. 2020, 28, 915-929. [CrossRef]

15. Jong, M.S.Y.; Tsai, C.C.; Xie, H.; Kwan-Kit Wong, F. Integrating interactive learner-immersed video-based virtual reality into learning and teaching of physical geography. Br. J. Educ. Technol. 2020, 51, 2064-2079. [CrossRef]

16. Geng, J.; Chai, C.S.; Jong, M.S.Y.; Luk, E.T.H. Understanding the pedagogical potential of Interactive Spherical Video-based Virtual Reality from the teachers' perspective through the ACE framework. Interact. Learn. Environ. 2019, 1-16. [CrossRef]

17. Steinitz, C. On Landscape Architecture Education and Professional Practice and Their Future Challenges. Land 2020, 9, 228. [CrossRef]

18. Carbonell-Carrera, C.; Saorin, J.L.; Hess-Medler, S. Spatial Orientation Skill for Landscape Architecture Education and Professional Practice. Land 2020, 9, 161. [CrossRef] 
19. Häkkilä, J.; Colley, A.; Väyrynen, J.; Yliharju, A.J. Introducing virtual reality technologies to design education. Seminar.net 2018, $14,1-12$.

20. Burdea, G.C.; Coiffet, P. Virtual Reality Technology; John Wiley \& Sons: Hoboken, NJ, USA, 2003.

21. Portman, M.E.; Natapov, A.; Fisher-Gewirtzman, D. To go where no man has gone before: Virtual reality in architecture, landscape architecture and environmental planning. Comput. Environ. Urban Syst. 2015, 54, 376-384. [CrossRef]

22. Smith, J.W. Immersive virtual environment technology to supplement environmental perception, preference and behavior research: A review with applications. Int. J. Environ. Res. Public Health 2015, 12, 1486. [CrossRef]

23. Lindquist, M.; Maxim, B.; Proctor, J.; Dolins, F. The effect of audio fidelity and virtual reality on the perception of virtual greenspace. Landsc. Urban Plan. 2020, 202, 103884. [CrossRef]

24. Munafo, J.; Diedrick, M.; Stoffregen, T.A. The virtual reality head-mounted display Oculus Rift induces motion sickness and is sexist in its effects. Exp. Brain Res. 2017, 235, 889-901. [CrossRef]

25. Farič, N.; Potts, H.W.; Hon, A.; Smith, L.; Newby, K.; Steptoe, A.; Fisher, A. What players of virtual reality exercise games want: Thematic analysis of web-based reviews. J. Med. Internet Res. 2019, 21, e13833. [CrossRef]

26. Lin, H.C.S.; Yu, S.J.; Sun, J.C.Y.; Jong, M.S.Y. Engaging university students in a library guide through wearable spherical video-based virtual reality: Effects on situational interest and cognitive load. Interact. Learn. Environ. 2019, 1-16. [CrossRef]

27. Ye, X.; Liu, F.; Lee, X.Z.; Zhang, Y.Q.; Chiu, C.K. Classroom misbehaviour management: An SVVR-based training system for preservice teachers. Interact. Learn. Environ. 2021, 29, 112-129. [CrossRef]

28. Chen, M.-R.A.; Hwang, G.-J. Effects of experiencing authentic contexts on English speaking performances, anxiety and motivation of EFL students with different cognitive styles. Interact. Learn. Environ. 2020, 1-21. [CrossRef]

29. Yang, G.; Chen, Y.T.; Zheng, X.L.; Hwang, G.J. From experiencing to expressing: A virtual reality approach to facilitating pupils' descriptive paper writing performance and learning behavior engagement. Br. J. Educ. Technol. 2021, 52, 807-823. [CrossRef]

30. Suh, A.; Prophet, J. The state of immersive technology research: A literature analysis. Comput. Hum. Behav. 2018, 86, 77-90. [CrossRef]

31. Lee, H.G.; Chung, S.; Lee, W.H. Presence in virtual golf simulators: The effects of presence on perceived enjoyment, perceived value, and behavioral intention. New Media Soc. 2013, 15, 930-946. [CrossRef]

32. Slater, M. Place illusion and plausibility can lead to realistic behaviour in immersive virtual environments. Philos. Trans. R. Soc. $B$ Biol. Sci. 2009, 364, 3549-3557. [CrossRef] [PubMed]

33. Servotte, J.C.; Goosse, M.; Campbell, S.H.; Dardenne, N.; Pilote, B.; Simoneau, I.L.; Ghuysen, A. Virtual reality experience: Immersion, sense of presence, and cybersickness. Clin. Simul. Nurs. 2020, 38, 35-43. [CrossRef]

34. Lan, Y.J. Immersion, Interaction, and Experience-Oriented Learning: Bringing Virtual Reality into FL Learning. Available online: http:/ / hdl.handle.net/10125/44704 (accessed on 1 February 2020).

35. Carbonell-Carrera, C.; Saorin, J.L.; Melián Díaz, D. User VR Experience and Motivation Study in an Immersive 3D Geovisualization Environment Using a Game Engine for Landscape Design Teaching. Land 2021, 10, 492. [CrossRef]

36. Greinert, A.; Mrówczyńska, M. The impact of the process of academic education on differences in landscape perception between the students of environmental engineering and civil engineering. Land 2020, 9, 188. [CrossRef]

37. Meyer, M.W.; Norman, D. Changing Design Education for the 21st Century. She Ji J. Des. Econ. Innov. 2020, 6, 13-49. [CrossRef]

38. Chang, S.C.; Hsu, T.C.; Kuo, W.C.; Jong, M.S.Y. Effects of applying a VR-based two-tier test strategy to promote elementary students' learning performance in a Geology class. Br. J. Educ. Technol. 2020, 51, 148-165. [CrossRef]

39. Fekete, A.; van den Toorn, M. Teaching Fieldwork in Landscape Architecture in European Context; Some Backgrounds and Organisation. Land 2021, 10, 237. [CrossRef]

40. Chang, Y.S.; Chou, C.H.; Chuang, M.J.; Li, W.H.; Tsai, I.F. Effects of virtual reality on creative design performance and creative experiential learning. Interact. Learn. Environ. 2020, 1-16. [CrossRef]

41. White, H.; Sabarwal, S. Quasi-Experimental Design and Methods, Methodological Briefs: Impact Evaluation 8; UNICEF Office of Research: Florence, Italy, 2014.

42. Cortina, J.M. What is coefficient alpha? An examination of theory and applications. J. Appl. Psychol. 1993, 78, 98. [CrossRef]

43. Hwang, G.-J.; Yang, L.-H.; Wang, S.-Y. A concept map-embedded educational computer game for improving students' learning performance in natural science courses. Comput. Educ. 2013, 69, 121-130. [CrossRef]

44. Barnard, L.; Lan, W.Y.; To, Y.M.; Paton, V.O.; Lai, S.-L. Measuring self-regulation in online and blended learning environments. Internet High. Educ. 2009, 12, 1-6. [CrossRef]

45. Mallery, P.; George, D. SPSS for Windows Step by Step; Allyn \& Bacon: Boston, MA, USA, 2000. Available online: https: / / dl.acm.org/doi/abs/10.5555/557542 (accessed on 30 September 2000).

46. Cohen, J. Statistical Power Analysis for the Behavioral Sciences; Academic Press: Salt Lake City, UT, USA, 2013.

47. Chen, M.; Chai, C.S.; Jong, M.S.Y.; Jiang, M.Y.C. Teachers' Conceptions of Teaching Chinese Descriptive Composition With Interactive Spherical Video-Based Virtual Reality. Front. Psychol. 2021, 12, 150. [CrossRef]

48. Chen, C.H.; Hung, H.T.; Yeh, H.C. Virtual reality in problem-based learning contexts: Effects on the problem-solving performance, vocabulary acquisition and motivation of English language learners. J. Comput. Assist. Learn. 2021. [CrossRef]

49. Chen, Y.-L.; Hsu, C.-C. Self-regulated mobile game-based English learning in a virtual reality environment. Comput. Educ. 2020, 154, 103910. [CrossRef] 
50. Zimmerman, B.J.; Schunk, D.H.; DiBenedetto, M.K. A personal agency view of self-regulated learning. In Self-Concept, Motivation and Identity: Underpinning Success Research and Practice; Information Age: Charlotte, NC, USA, 2015; pp. 83-114.

51. Mondellini, M.; Mottura, S.; Guida, M.; Antonietti, A. Influences of a Virtual Reality Experience on Dissociation, Mindfulness, and Self-Efficacy. Cyberpsychology Behav. Soc. Netw. 2021. [CrossRef] [PubMed]

52. Huang, H.M.; Liaw, S.S. An analysis of learners' intentions toward virtual reality learning based on constructivist and technology acceptance approaches. Int. Rev. Res. Open Distrib. Learn. 2018, 19. [CrossRef]

53. Huang, C.L.; Luo, Y.F.; Yang, S.C.; Lu, C.M.; Chen, A.S. Influence of students' learning style, sense of presence, and cognitive load on learning outcomes in an immersive virtual reality learning environment. J. Educ. Comput. Res. 2020, 58, 596-615. [CrossRef] 